\title{
The Polymer Effect. I. The Acceleration Effect of Poly(vinylpyrrolidone) on a Williamson's Reaction
}

\author{
Noboru Yamazaki, Akira Hirao, and Seiichi Nakahama \\ Department of Polymer Science, Tokyo Institute of Technology, \\ Ookayama, Meguro-ku, Tokyo 152, Japan.
}

(Received December 20, 1974)

\begin{abstract}
The additive effect of poly(vinylpyrrolidone) (PVPD) to a Williamson's reaction, ether synthesis from sodium phenoxide and $n$-butyl bromide, in dioxaneethanol mixed solution at $45^{\circ} \mathrm{C}$ has been investigated, and compared with that of $\mathrm{N}$ methylpyrrolidone (NMPD), which is a monomeric analogue of PVPD.

A marked acceleration effect of PVPD on the rate of the reaction was observed in dioxane, which was about 100 times greater than that of NMPD at a concentration of $0.135 \mathrm{~mol} / \mathrm{l}$. Evidence is presented to show that the remarkable rate acceleration by PVPD is produced owing not only to the enrichment of the phenoxide in the polymer domain due to the complexation of sodium cation with pyrrolidone unit of the polymer, but also to the dissociation of sodium phenoxide based on the tight solvation of sodium cation with a pyrrolidone unit in the contracted polymer coil.

KEY WORDS Polymer Effect / Acceleration / Poly(vinylpyrrolidone)/

Solvation / Complexation / Williamson's Reaction / Viscosity. /
\end{abstract}

It is well known that $S_{N} 2$ type reactions are remarkably accelerated due to specific solvation of cationic species by dipolar aprotic solvents, such as $N, N$-dimethylformamide, $N, N$-dimethylacetamide, $N$-methylpyrrolidone (NMPD), and hexamethylphosphortriamide (HMPA). ${ }^{1,2}$ However, few investigations have been reported on the acceleration effects from polymers containing these polar groups as the pendant or in the main chain, such as $\operatorname{poly}(N, N$-dimethylacrylamide $), \operatorname{poly}(N$ vinylpyrrolidone) (PVPD), and poly(HMPA). ${ }^{3}$

Thus, we have been interested in the special behavior of the solvent molecule around the site of an $\mathrm{S}_{\mathrm{N}} 2$ reaction, when the solvent molecule was incorporated into a polymer chain or as a pendant of a polymer. Naturally the situation of a solvent molecule unit connected to the polymer around the reaction site might be regulated by the interaction with the substrate and the conformation of the polymer. Such regulation may be called the "polymer effect", which involves binding and enrichment of the substrate and results in acceleration of the reaction.

The polymer effects have been investigated in the hydrolysis of esters using poly(vinylimidazole) as a catalyst ${ }^{4}$ and in the primary salt effect on the rate of reaction between similarly charged ionic species by polyelectrolytes. ${ }^{5}$

In the present paper, we describe the additive effect of poly(vinylpyrrolidone) on a Williamson's reaction, a typical $S_{\mathbb{N}} 2$ reaction, ether synthesis from sodium phenoxide and $n$-butyl bromide, and compare it with that of $N$-methylpyrrolidone, which is a monomeric analogue.

\section{EXPERIMENTAL}

\section{Materials}

Dioxane was refluxed over $\mathrm{Na}$ and distilled from $\mathrm{LiAlH}_{4}$. Ethanol was refluxed over $\mathrm{Mg}\left(\mathrm{OC}_{2} \mathrm{H}_{5}\right)_{2}$ and distilled. $n$-Butyl bromide and $\mathrm{N}$-methylpyrrolidone (NMPD) were purified by drying over $\mathrm{CaH}_{2}$ overnight and distillation. Sodium phenoxide (PhONa) was prepared by the procedure of Vogel. ${ }^{6}$ PVPD was obtained by heating vinylpyrrolidone and AIBN at $85^{\circ} \mathrm{C}$ for $24 \mathrm{hr}$. PVPD was purified by repeated precipitation of a dioxane solution into a large amount of diethyl ether and was dried in vacuo at $100^{\circ} \mathrm{C}$ for $24 \mathrm{hr}$. The intrinsic viscosity of the PVPD in $\mathrm{H}_{2} \mathrm{O}$ at $30^{\circ} \mathrm{C}$ was $0.225 \mathrm{~d} l / \mathrm{g}$, corresponding to a viscosity-average molecular weight of 47,000 . 


\section{Kinetic Measurement}

A solution of $n$-butyl bromide containing PVPD as an additive (or NMPD) in dioxane and ethanol was stirred in a thermostatted flask at $45.0 \pm$ $0.1^{\circ} \mathrm{C}$. When the temperature of the solution reached the bath temperature, a PhONa solution was added into the solution. At suitable intervals, the reaction mixtures were withdrawn and added to excess $\mathrm{HCl}$ solutions containing methyl red as an indicator. Excess acid was then backtitrated with a $\mathrm{NaOH}$ solution. For each run, the slope and standard deviation of the plot of the logarithm of the concentration of unreacted $\mathrm{PhONa}$ against time in minutes was calculated by the statistical method of least squares. The pseudo-first-order constant, $k_{1}$, was directly calculated from this slope. The reaction and the reaction rate are represented by

$$
\mathrm{PhONa}+n-\mathrm{C}_{4} \mathrm{H}_{9} \mathrm{Br} \stackrel{k_{1}}{\longrightarrow} n-\mathrm{C}_{4} \mathrm{H}_{9} \mathrm{OPh}+\mathrm{NaBr}
$$

The reaction rate $=k_{1}[\mathrm{PhONa}]$

The concentrations of $\mathrm{PhONa}, n$-butyl bromide, and the additive (PVPD or NMPD) were 0.025, 0.280 , and $0.025-1.08 \mathrm{~mol} / l$, respectively. The total volume was $20 \mathrm{ml}$. All the operations except for the titration were carried out in an atmosphere of prepurified nitrogen.

\section{RESULTS AND DISCUSSION}

The pseudo-first-order rate constants for Williamson's reaction in dioxane, ethanol, and their mixture in the presence of additives (NMPD or PVPD) are listed in Table I. The rate con-

Table I. The rate constants and the acceleration factor in dioxane-ethanol mixed solution at $45^{\circ} \mathrm{C}^{\mathrm{a}}$

\begin{tabular}{ccccc}
\hline No. $\begin{array}{c}\text { Dioxane } \\
\text { content, } \\
\%\end{array}$ & \multicolumn{2}{c}{$\begin{array}{c}\text { Rate constant, } \\
\times 10^{4} \mathrm{~min}^{-1}\end{array}$} & $\begin{array}{c}\text { Acceleration } \\
\text { factor, } \\
k_{\mathrm{p}} / k_{\mathrm{N}}\end{array}$ \\
\hline 1 & 100 & 1.69 & 169 & 100 \\
2 & 85 & 2.28 & 26.7 & 11 \\
3 & 75 & 2.50 & 13.0 & 5.2 \\
4 & 50 & 2.50 & 5.7 & 2.3 \\
5 & 0 & 2.50 & 2.9 & 1.2 \\
\hline
\end{tabular}

a Conditions of reaction: [PhONa], $0.025 \mathrm{~mol} / l$; $\left[n-\mathrm{C}_{4} \mathrm{H}_{9} \mathrm{Br}\right.$ ], $0.280 \mathrm{~mol} / l ;$ [additive], $0.135 \mathrm{~mol} / l$; total volume, $20 \mathrm{~m} l$. stants, $k_{\text {blank }}, k_{\mathrm{NMPD}}$, and $k_{\mathrm{PVPD}}$ are those in the absence and in the presence of NMPD and PVPD, respectively. The ratio, $\left[k_{\mathrm{PVPD}}-k_{\mathrm{blank}}\right] /\left[k_{\mathrm{NMPD}}-\right.$ $\left.k_{\text {blank }}\right]=k_{\mathrm{p}} / k_{\mathrm{N}}$, denotes the magnitude of the polymer effect, which we would now call an acceleration factor of PVPD.

An extraordinarily marked additive effect of PVPD was demonstrated in dioxane; the acceleration factor increased up to 100 (No. 1 in Table I). This decreased significantly by the addition of a small amount of ethanol to the reaction system and further decreased by increasing the ethanol content (No. 2-4). No acceleration was observed in ethanol alone (No. 5). As $k_{N}$ was almost constant at all compositions of the mixed solution, the acceleration factor depended mainly on the value of $k_{\mathrm{p}}$.

It is to be mentioned that the marked additive effect in dioxane was accompanied by precipitation, when $\mathrm{PhONa}$ was introduced into the solution of PVPD, whereas the reaction system including ethanol proceeded in homogeneous solutions. The anomalous behavior of the heterogeneous reaction will be described later in detail.

The dependence of the rate constants and the acceleration factor on the additive concentration are illustrated in Figures 1 and 2, respectively. The rate constant $k_{\mathrm{p}}$ increased with the concentration of PVPD and the enhancement was

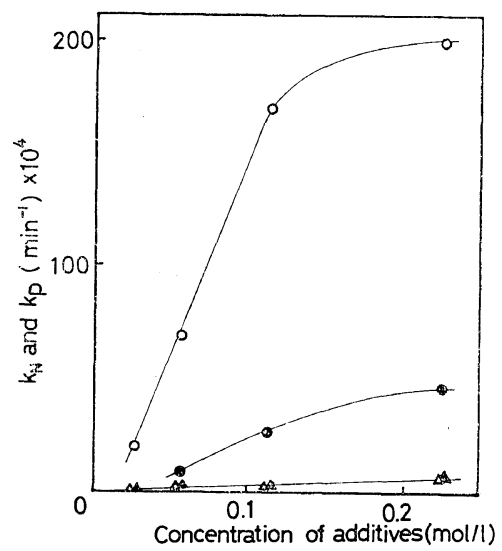

Figure 1. The dependence of $k_{\mathrm{N}}$ and $k_{\mathrm{p}}$ on additive concentration at $45^{\circ} \mathrm{C}:-\bigcirc-, k_{\mathrm{p}}$ in dioxane; $-\longrightarrow, k_{\mathrm{p}}$ in dioxane-ethanol $(85 / 15, \mathrm{v} / \mathrm{v}) ;-\triangle-$, $k_{\mathrm{N}}$ in dioxane; -,$- k_{\mathrm{N}}$ in dioxane-ethanol $(85 / 15, \mathrm{v} / \mathrm{v})$. 


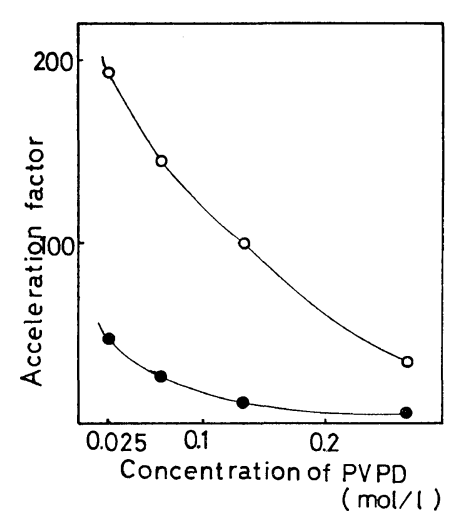

Figure 2. The dependence of the acceleration factor of PVPD on concentration at $45^{\circ} \mathrm{C}:-\bigcirc-$, in dioxane; - - in dioxane-ethanol $(85 / 15, \mathrm{v} / \mathrm{v})$.

remarkable, especially in dioxane, whereas the rate constant $k_{\mathrm{N}}$ was extremely small as compared with $k_{\mathrm{p}}$ in the same concentration ranges (Figure 1).

As shown in Figure 2, the acceleration factor of PVPD was very large in dioxane at the low concentrations and it decreased sharply with increasing concentration of PVPD. A similar behavior to that in dioxane was observed in dioxane-ethanol $(85 / 15, \mathrm{v} / \mathrm{v})$, but this was not so significant. Below the concentration of 0.025 $\mathrm{mol} / l$, the value of $k_{\mathrm{p}} / k_{\mathrm{N}}$ was unreliable owing to the experimental error for $k_{\mathrm{N}}$.

As mentioned before, fine precipitates were obtained by the addition of $\mathrm{PhONa}$ to the dioxane solution of PVPD. The precipitate was separated through a sintered glass filter under nitrogen atmosphere, washed with dry dioxane, and freed from the solvent in vacuo at room temperature. From the IR spectrum of the product and acid-base titration of the filtrate, the precipitate was found to be composed of PVPD and PhONa, and neither PVPD nor PhONa was observed in the filtrate or in the washing solution. Since both PVPD and PhONa are separately soluble in dioxane, it may be considered that the precipitate is a complex which is formed by the solvation of sodium cation of PhONa with pyrrolidone unit of PVPD. Conversely, desolvation of the dioxane molecule from the polymer domain by the complexation of PVPD with PhONa results in the precipitation of the polymer itself.
The formation of such a complex can also be substantiated by the existance of the NMPDPhONa $(1: 1)$ complex. When the dioxane solution of $\mathrm{PhONa}$ was added to NMPD at room temperature, white crystalline needles precipitated immediately; these were recrystallized from dry benzene and carefully washed with dry $n$-hexane under nitrogen atmosphere.

Anal. Calcd for PhONa.NMPD: N, 6.64\%. Found: N, 6.74\%.

The complexation of PhONa and PVPD was expected to occur in dioxane-ethanol mixed solutions as well as in dioxane. In order to examine this, an insoluble PVPD gel, which was cross-linked with $p$-divinylbenzene, was adopted instead of PVPD. The fraction of PhONa complexed with this PVPD gel in dioxaneethanol at various compositions was determined by the filtration of the insoluble mixture, which was considered a complex of PVPD gel with PhONa, and by the titration of PhONa in the filtrate.

As shown in Table II, PhONa was complexed as thoroughly with the PVPD gel in dioxane as with linear PVPD. Although the fraction of the trapped $\mathrm{PhONa}$ in the polymer due to complexation was reduced by decreasing the dioxane content, $37 \%$ of $\mathrm{PhONa}$ still remained in the polymer in ethanol.

The acceleration factor of PVPD for

Table II. The relationship between the fraction of trapped PhONa in PVPD gel and the acceleration factor in dioxaneethanol mixed solution ${ }^{a}$

\begin{tabular}{cccc}
\hline No. & $\begin{array}{c}\text { Dioxane } \\
\text { content, } \\
\%\end{array}$ & $\begin{array}{c}\text { Fraction of } \\
\text { trapped PhONa } \\
\text { in PVPD gel, } \%\end{array}$ & $\begin{array}{c}\text { Acceleration } \\
\text { factor of } \\
\text { PVPD }^{b}\end{array}$ \\
\hline 1 & 100 & 100 & 100 \\
2 & 85 & 81 & 11 \\
3 & 50 & 45 & 2.3 \\
4 & 0 & 37 & 1.2 \\
\hline
\end{tabular}

a Reaction conditions; Insoluble PVPD gel, 15\% cross-linked with $p$-divinylbenzene, was used; pyrrolidone unit in the gel, $2.7 \mathrm{mmol}$; $\mathrm{PhONa}$, $0.5 \mathrm{mmol}$; temp., $45^{\circ} \mathrm{C}$; total volume, $20 \mathrm{ml}$.

b The acceleration factor values of this column are the same as those in Table I, where vinylpyrrolidone homopolymer was used. 
Williamson's reaction also diminished with decreasing dioxane content (Table II). Since the value of the acceleration factor was not proportional to the amount of PhONa trapped in the polymer domain, the complexation of $\mathrm{PhONa}$ might not be the only factor contributing to the enhancement of the reaction. Actually the acceleration was reduced to one-tenth of the original value (No. 1 and 2 in Table II) when only $19 \%$ of $\mathrm{PhONa}$ was released from the polymer domain. No enhancement was observed in ethanol, though $37 \%$ of $\mathrm{PhONa}$ was still distributed in the polymer domain (No. 4 in Table II).

Generally the so-called polymer effect on the chemical reaction is known to be influenced by conformation of its polymer in the reaction systems. ${ }^{7}$ The viscosities of PVPD with PhONa in a variety of dioxane-ethanol mixed solutions were measured to determine the effect of polymer conformation. The results obtained are shown in Figure 3. The viscosity number, $\eta_{\mathrm{sp}} / C$, increases markedly with the ethanol content. It may be assumed that PVPD exists in a contracted form due to the complexation with $\mathrm{PhONa}$ in dioxane-ethanol of $85 / 15$ (by vol \%) and is expanded with the increasing amount of ethanol. The resulting viscosity number of the polymer in the presence of PhONa was found to be fairly closely associated with the acceleration factor, as shown in Figure 4. These results suggest that a contracted form of the polymer coil should be favorable for an acceleration of the reaction.

The precipitate of PVPD accompanied with $\mathrm{PhONa}$ in dioxane is considered to be an extremely contracted form of the polymer, where

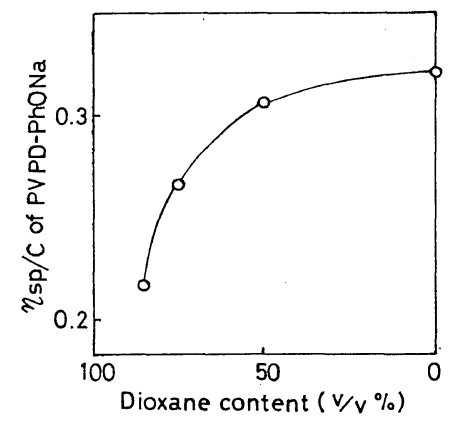

Figure 3. The viscosity of PVPD with $\mathrm{PhONa}$ in dioxane-ethanol mixed solution at $45^{\circ} \mathrm{C}$ : [PVPD]/[PhONa], 5.4; $C, 1.0 \mathrm{~g} / \mathrm{d} l$.

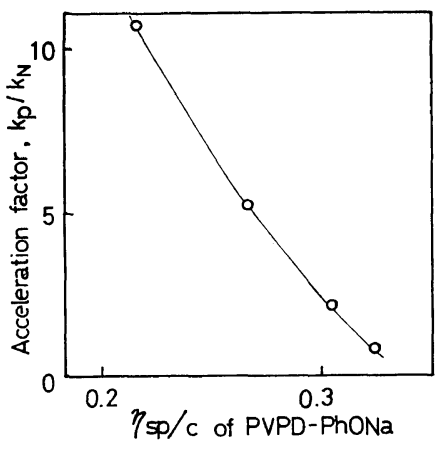

Figure 4. The relationship between the viscosity number of PVPD-PhONa and the acceleration factor in dioxane-ethanol mixed solution at $45^{\circ} \mathrm{C}$ : [PVPD]/[PhONa], 5.4; $C, 1.0 \mathrm{~g} / \mathrm{d} l$.

the sodium ion may be tightly solvated with several pyrrolidone units. The tight solvation of the cation promotes the dissociation of $\mathrm{PhONa}$ to form a "bare phenolate anion," which is a labile species, leading to the marked enhancement of the reaction. Such a result was also supported by the data from a separate experiment, in which the UV spectra of $\mathrm{PhONa}$ changed continuously depending on the mole ratio of PVPD and PhONa.

It might be also considered that the reactivity of $n$-butyl bromide with PVPD is influenced by the formation of the onium salt with pyrrolidone units. Details of the investigations of the UV spectroscopy of the PhONa in the presence of PVPD in various solvents and on the formation of the onium salt will be reported in the near future.

\section{REFERENCES}

1. A. J. Parker, Chem. Rev., 69, 1 (1969).

2. R. S. Kittila, “DMF”, E. I. Dupont de Nemour \& Co., Wilmington, Deleware, 19898 (1967).

3. A. Bello, W. Bracke, J. J. Grodzinski, G. Sackmana, and M. Szwarc, Macromolecules, 3, 98 (1970).

4. C. G. Overberger, M. Morimoto, I. Chou, and J. C. Salamone, ibid., 2, 553 (1969).

5. N. Ise and F. Matsui, J. Amer. Chem. Soc., 90, 4242 (1968).

6. C. Vogel, Ph. D. Thesis, Purdue University, June, 1960.

7. Yu. E. Krish, S. K. Plujinov, T.S. Schomia, V. A. Kabanov, and V. A. Kargin, Vysokomol. Soedin, Ser. A, 12, 186 (1970). 